\title{
La distribución de costes públicos y privados en la crisis del Covid-19
}

\author{
The distribution of public and private costs \\ in the Covid-19 crisis
}

\author{
Jesús Lahera Forteza* \\ Catedrático Acreditado (por Recurso) Derecho Trabajo Universidad Complutense
}

ORCID ID: 0000-0002-9734-3952

Recibido: $30 / 4 / 2020$

Aceptado: 6/5/2020

doi: https://doi.org/10.20318/labos.2020.5537

Esesumen: análisis parte de la perspectiva de la distribución de costes laborales en la
crisis sanitaria y económica del coronavirus. El Estado ha asumido parte de
estos costes sobre todo a través de ERTES con protección social por desempleo
y prestaciones sociales de autónomos. Pero las empresas, autónomos y trabaja-
dores soportan también costes significativos. Planteo, de cara al futuro de la re-
cuperación gradual, medidas que repartan de manera más equitativa los costes
públicos y privados de un parón económico inducido por el propio Estado por
motivos de salud pública.

Palabras clave: coste laboral, coronavirus, protección social.

Abstract: This analysis starts from the perspective of the distribution of labor costs in the coronavirus health and economic crisis. The State has assumed part of these costs, especially through ERTES with social protection for unemployment and social benefits for the self-employed. But companies, freelancers and workers also bear significant costs. I propose, with a view to the future of gradual recovery, measures that distribute the public and private costs of an economic downturn induced by the State itself for reasons of public health more equitably.

Keywords: labor cost, coronavirus, social protection.

\section{La perspectiva de la distribución de costes en las medidas laborales y sociales adoptadas ante la crisis del COVID-19}

El Gobierno Español ha aprobado, desde el 17 de Marzo hasta el 12 de Mayo de 2020, una serie de Reales Decretos-Ley de contenido laboral y social, en el contexto del estado de alarma articulado en el Real Decreto 463/2020 (BOE 14 Marzo) para gestionar la crisis del COVID-19, luego prorrogado sucesivamente, en períodos de quince días, hasta, al menos, el 21 de Junio, siendo previsible su finalización a finales de Junio.

jesuslahera@cps.ucm.es 
- El Real Decreto-Ley 8/2020 (BOE 18 de Marzo, en adelante DLA 8) articula medidas laborales y sociales.

- Estas medidas han sido complementadas por el Real Decreto-Ley 9/2020 (BOE 27 de Marzo, en adelante DLA 9) y por el Real Decreto-Ley 10/2020 (BOE 29 de Marzo, en adelante DLA 10), una vez decidida la paralización de trabajo presencial en actividad no esencial desde el 30 de Marzo hasta el 9 de Abril.

- Se han adoptado medidas sociales añadidas luego en Real Decreto-Ley 11/2020 (BOE 1 Abril, en adelante DLA 11), con algunos cambios en el Real Decreto-Ley 13/2020 (BOE 8 Abril, en adelante DLA 13).

- El Real Decreto-Ley 15/2020 (BOE 22 Abril, en adelante DLA 15) reforma algunos aspectos de estas normas y añade alguna otra medida social.

- El Real Decreto-Ley 18/2020 (BOE 13 Mayo, en adelante DLA 18) es la primera norma laboral y social de la desescalada y vuelve a modificar aspectos del DLA

Toda esta normativa de urgencia responde al paradigma europeo de flexiseguridad, que combina flexibilidad laboral y protección social. La crisis sanitaria, que ha obligado a suspender o restringir numerosas actividades empresariales y que ha ocasionado un gran impacto en los mercados, ha obligado al Gobierno a utilizar herramientas de respuesta flexible, con una distribución de costes privados y públicos.

Las medidas adoptadas han buscado que el impacto de la suspensión o restricción de actividades empresariales durante el estado de alarma, así como el de la propia crisis sanitaria y económica, se canalice en el ámbito del empleo preferentemente a través de los ERTES, que combinan reducciones de jornada o suspensiones del contrato de trabajo con el reconocimiento a los trabajadores afectados de una protección social específica por desempleo ${ }^{1}$. En los autónomos también se ha derivado parte de los efectos de la crisis hacia la protección social de cese de actividad ${ }^{2}$. Como así ha sucedido, a través de la cobertura extraordinaria de protección por desempleo, en los fijos discontinuos afectados y no afectados por ERTES y que ven interrumpida su actividad o no son llamados a trabajar debido a la crisis del COVID-19³.

Las necesidades excepcionales de conciliación familiar y laboral exigidas por el cierre durante el estado de alarma de los centros educativos y otros análogos, como es el caso de los centros de día para personas mayores, y por la propia crisis sanitaria, se han pretendido atender mediante el desarrollo de procedimientos específicos de adaptación de las condiciones de trabajo y reducciones de jornada por cuidado relacionado con el coronavirus, a iniciativa de la persona trabajadora ${ }^{4}$.

De manera transversal, se ha instaurado, en esta situación excepcional, un deber empresarial de implantar teletrabajo siempre que sea posible, a fin de garantizar la salud pública reduciendo los desplazamientos por motivo laboral, y, a la vez, facilitar la propia conciliación familiar y laborals.

De manera acotada en el tiempo, se articula un permiso retribuido recuperable ante la prohibición de trabajo presencial en actividades no esenciales desde el 30 de Marzo hasta el 9 de Abril ${ }^{6}$.

${ }^{1}$ Arts. 22-25 y DA 6a DLA 8 modificados por DA 14 DLA 11, DF 8.2 DLA 15 y DF.1 DLA 18. Vigencia hasta 30 de Junio (art. 2 y 3 DLA 18) salvo prórrogas adicionales acordadas por Gobierno.

${ }^{2}$ Art. 17 DLA 8 modificado por DF 2a DLA 13 y DA 10a y DF 8.1 DLA 15. Vigencia hasta el último día del mes en que finalice estado de alarma, por tanto ya 30 de Junio

${ }^{3}$ Art.25.6 DLA 8 y DF 8.3 DLA 15 y art. 3 DLA 18.Vigencia hasta 31 Diciembre

${ }^{4}$ Art.6 DLA 8 con prórroga DLA 11 y art.15 DLA 15 (3 meses tras fin de estado de alarma)

${ }^{5}$ Art. 5 DLA con prórroga DLA 11 y art. 15 DLA 15 (3 meses tras fin de estado de alarma)

${ }^{6}$ Art. 2 y 3 DLA 9 
Las medidas se acompañan, finalmente, de subsidios específicos en trabajadores temporales y servicio doméstico sin cobertura de protección social por desempleo ${ }^{7}$, así como la cobertura por desempleo de trabajadores que vieron extinguidos sus contratos con período de prueba a partir de 9 de Marzo ${ }^{8}$.

Las cinco líneas de acción política coinciden con directrices del paradigma europeo de flexiseguridad laboral ${ }^{9}$ ante una crisis: combinar flexibilidad laboral con protección social para salvar empleos, atender las necesidades excepcionales de conciliación familiar, aprovechar herramientas de flexibilidad tecnológica como el teletrabajo, intensificar la distribución irregular de la jornada con flexibilidad en el tiempo de trabajo y atender con subsidios específicos a los más vulnerables ${ }^{10}$. Las medidas redistribuyen, así, los costes laborales y sociales, públicos y privados, en una situación laboral excepcional.

Este estudio parte de la perspectiva de la distribución de costes públicos y privados derivada de esta crisis sanitaria y económica. Para ello, expongo brevemente el marco jurídico de las medidas adoptadas, sin profundizar en su problemática teórica o práctica ${ }^{11}$, y efectúo, exclusivamente, un análisis de la distribución efectuada de costes, públicos y privados, con una reflexión de futuro, ante la recuperación paulatina y gradual que nos espera.

\section{Las medidas laborales y sociales adoptadas en la crisis del COVID-19}

\subsection{ERTES especificos con protección social}

El ERTE suspensivo o de reducción de jornada es una medida idónea para salvar empleos durante una crisis. Es por ello que las reformas de 2010 y 2012 facilitaron su uso y flexibilizaron sus procedimientos en el marco del art. 47 ET y el RD 1483/2012. Ante esta crisis sanitaria, el Gobierno actual sigue esta línea y ofrece esta herramienta flexible a las empresas para salvar empleos. Para ello, los arts. 22 y 23 DLA 8 diferencian entre ERTES de fuerza mayor y causa empresarial relacionada con COVID-19, con protección social reforzada de desempleo en ambos supuestos.

El ERTE, de suspensión contractual o reducción de jornada, específico por fuerza mayor del art. 22 DLA 8 necesita autorización administrativa a solicitud de la empresa, como es regla general en el art. 47.3 y 51.7 ET. La "fuerza mayor" que motiva un ERTE responde a supuestos de hecho con causa directa en el coronavirus o en las medidas de estado de alarma del Real Decreto 463/2020. Hay, así, dos tipos de ERTE específico por fuerza mayor.

El primero, el estrictamente sanitario, se ampara "en situaciones urgentes y extraordinarias debidas al contagio de la plantilla o la adopción de medidas de aislamiento preventivo decretados por la autoridad sanitaria". El cierre temporal de un centro de trabajo decretado por este motivo sanitario justifica un ERTE suspensivo por fuerza mayor.

El segundo, el que tiene causa directa en las medidas del estado de alarma. Las pérdidas, totales o parciales, de actividad como consecuencia de la declaración de estado de alarma que

\footnotetext{
${ }^{7}$ Arts.30-33 DLA 11

${ }^{8}$ Art. 22 DLA 11

${ }_{9}^{9}$ Sobre este paradigma europeo, por todos, VALDES, F; LAHERA, J, La flexiseguridad laboral en España, Fundación Alternativas, 2010

${ }^{10}$ Analizo las medidas adoptadas desde este paradigma en LAHERA FORTEZA, J, "Flexiseguridad laboral ante la crisis del coronavirus", Derecho de Relaciones Laborales, 2020, no 4 Abril, p.419-429

${ }^{11}$ Un excelente tratamiento monográfico de varios profesores de esta acción normativa laboral y social ante el coronavirus, impulsado por CASAS BAAMONDE, M.E, en Derecho de Relaciones Laborales 2020, nº Abril. Estas medidas han sido comentadas también, con detalle, en las entradas de Marzo, Abril y Mayo en los blogs jurídicos laborales de Eduardo Rojo, Antonio Baylos, Ignasi Beltrán, Adrián Todolí, Jesús Cruz Villalón y Foro de Labos.
} 
impliquen "suspensión o cancelación de actividades, cierre temporal de locales de afluencia pública, restricciones en el transporte público y, en general, de la movilidad de las personas y mercancías y la falta de suministro que impidan gravemente continuar con el desarrollo ordinario de la actividad" justifican un ERTE suspensivo o de reducción de jornada por fuerza mayor. A ello hay que ańadir los supuestos en actividades esenciales mantenidas "de la parte de actividad no afectada" por esta exigencia. Son ERTES que se están aplicando en las numerosas actividades empresariales suspendidas (hostelería, sector hotelero, comercio minorista, espectáculos de ocio y deportivos, turismo cultural etc.) o restringidas (transporte) pero, también, en las de los proveedores y contratistas de las mismas (todo tipo de servicios), así como en supuestos de falta de suministro por el estado de alarma que impide la producción (sector industrial, sobre todo), a lo que ańadir la más reciente admisión en casos de afectación parcial en actividades mantenidas (por ejemplo, parte paralizada de sector alimentario).

El procedimiento de constatación administrativa de la fuerza mayor es urgente, cinco días, y la ausencia de respuesta de la autoridad laboral es silencio positivo. La empresa puede suspender contratos de trabajo o, si es posible, reducir jornada, accediendo los trabajadores a situación de desempleo total o parcial. La medida, en el marco del art. 25 DLA 8, se acompańa de la eliminación del período de carencia para el acceso al desempleo y establece la reposición de la prestación al reanudarse la actividad, poniendo el contador a cero. También, como afirma el art. 26 DLA 8, se exonera de las cuotas de seguridad social a la empresa, pero con el compromiso de mantener el empleo seis meses con posterioridad como declara la DA 6a DLA 8, luego aclarada en la DF.1 DLA 18 y pendiente todavía de mayor concreción en sectores de alta variabilidad y estacionalidad. Se consigue, así, flexibilidad laboral interna salvando empleos, protección social de los afectados y descarga de costes empresariales asumidos por el Estado en una situación crítica.

Por su parte, todo aquel ERTE relacionado con el COVID-19, que no responda a una fuerza mayor, se articula a través de otro procedimiento específico, en el art. 23 DLA 8, que, como es regla general en el art. 47. 1 y 2 ET, no necesita de autorización administrativa. Se abre período breve de consultas, máximo siete días, con los representantes de los trabajadores para alcanzar acuerdo y, en su defecto, decide la empresa, sin perjuicio de impugnación judicial. Si no hay representantes, tiene prioridad una mesa sindical del sector en las consultas o, en su defecto, los comités ad hoc elegidos en asamblea, fórmula ya prevista en el art. 41.4 ET, aunque de manera más directa sin este paso previo sindical. Las caídas de demanda y consumo y reestructuraciones productivas debidas al contexto económico de coronavirus están motivando también muchos ERTES específicos con suspensiones y reducciones de jornada. La protección social por desempleo es idéntica a uno de fuerza mayor, como declara el art. 25 DLA 8, pero no hay exoneración de cuotas empresariales. Se consigue, también así, combinar flexibilidad laboral y protección social para salvar empleos, siendo criticable que no se hayan descargado también aquí costes empresariales.

La prohibición de despidos por las causas de estos ERTES del art.2 DLA 9 tiene un alcance relativo. Implica que estos despidos individuales o colectivos sean improcedentes, pasando la indemnización de 20 a 33 días salario/año, sin que se haya impuesto la nulidad con readmisión y salarios. Y no descarta despidos por causas empresariales, individuales o colectivo, de los arts. 52.c y 51 ET, tras el estado de alarma.

El DLA 18 ha desvinculado el estado de alarma de estos ERTES por fuerza mayor, siendo prorrogados hasta el 30 de Junio, sin perjuicio de prórrogas adicionales por el Gobierno, previa consulta con una comisión específica a estos efectos de composición tripartita. Como primera norma laboral de la desescalada, ha diferenciado los ERTES por fuerza mayor total, sin retorno de actividad, y parcial, con desafección gradual de trabajadores, con reglas específicas de exoneración porcentual de cuotas sociales. 


\subsection{Medidas especificas de conciliación familiar}

Las medidas de conciliación familiar giran, en nuestro ordenamiento, en torno a las reducciones de jornada por cuidado de hijo menor de doce años o familiar dependiente de los arts. 37.6 y 7 ET, y los más novedosos procedimientos de adaptación de la jornada y condiciones laborales por esta razón a solicitud del trabajador del art. 34.8 ET. La crisis sanitaria ha conllevado medidas como el cierre de colegios que han intensificado las responsabilidades familiares de los trabajadores/as. Es por ello que el Gobierno, sobre esta base, ha intensificado estas medidas de conciliación familiar y laboral en el art. 6 DLA 8, vigentes tres meses después de la finalización del estado de alarma tras el art. 15 DLA 15.

Se articulan medidas específicas de conciliación familiar de adaptación y reducción de jornada a las "personas trabajadoras por cuenta ajena que acrediten deberes de cuidado respecto del cónyuge o pareja de hecho, asi como respecto de los familiares por consanguinidad hasta el segundo grado". El ejercicio de estos derechos está fundamentado en las circunstancias excepcionales de necesidad de presencia del trabajador/a para la atención de estas personas "por razón de edad, enfermedad o discapacidad" y cuidado personal y directo como "consecuencia del coronavirus". También se pueden fundamentar en deberes de cuidado y atención ante las medidas del estado de alarma de "cierre de centros educativos o de cualquier otra naturaleza". Son derechos individuales, fundamentados en estos motivos con un ejercicio "justificado, razonable y proporcionado a la situación de la empresa".

Se permite, de un lado, al trabajador/a solicitar la "adaptación" de su jornada, horario o condiciones laborales, incluido teletrabajo, para atender este cuidado, incentivando acuerdos urgentes con la empresa. De otro lado, se reconoce una "reducción de jornada" por cuidado que puede alcanzar el 100 por 100 de jornada, con disminución proporcionada de salario sin protección social. Se ofrece así flexibilidad al trabajador para adaptarse a esta situación, lo que va a obligar a las empresas a una gran flexibilidad organizativa interna o a contrataciones temporales de interinos. Las medidas no van acompañadas de ayudas sociales a quienes ejercen estos derechos específicos de conciliación familiar durante la crisis sanitaria.

\subsection{Prioridad del teletrabajo}

El teletrabajo está regulado en el art. 13 ET y es una herramienta de flexibilidad tecnológica siempre útil para empresas y trabajadores en nuestra sociedad digital. La crisis sanitaria, sobre este terreno, ha propiciado que el Gobierno potencie esta herramienta, en línea con lo que ya muchas empresas estaban haciendo por sí mismas.

Se establece así, en el art. 5 DLA 8, el deber empresarial de implantar teletrabajo en su organización durante el estado de alarma. Las empresas "establecerán sistemas de organización que permitan mantener la actividad por mecanismos alternativos, particularmente por medio del trabajo a distancia, debiendo adoptar las medidas oportunas si ello es técnicamente y razonablemente posible y el esfuerzo de adaptación es proporcionado". El teletrabajo es, así, "prioritario", respecto a los ERTEs, y aparece, también, como medida preferente de conciliación laboral y familiar y de protección de salud pública. La medida estará vigente tres meses después de finalización del estado de alarma tras el art. 15 DLA 15.

Se intentan evitar así desplazamientos a los centros de trabajo, lo que favorece la salud pública, al disminuir los riesgos de contagios. Y, a la vez, se trata de facilitar la conciliación familiar y laboral en este escenario de cierre escolar.

La medida va acompañada de un Plan Acelera de ayudas públicas a las Pymes para inversiones tecnológicas en teletrabajo. 


\subsection{Permiso retribuido recuperable y distribución irregular de la jornada}

La distribución irregular de la jornada es una herramienta de flexibilidad en el tiempo de trabajo incorporada en las reformas de 2010 y 2012 y regulada en el art.34.2 ET. La negociación colectiva establece el sistema de distribución irregular y, en su defecto, se aplica el 10 por 100 previsto legalmente con un preaviso de 5 días. El Gobierno acude a esta vía para afrontar el parón económico entre el 30 Marzo y 9 Abril en actividades no esenciales mediante el denominado "permiso retribuido recuperable" de los arts. 2 y 3 DLA 10.

Las actividades esenciales son tasadas en el anexo DLA 10 y la medida afecta a trabajadores del resto que no realicen teletrabajo ni estén afectadas por ERTE. Implica no trabajar, entre el 30 de marzo y el 9 de abril, cobrando el salario, para luego recuperar esas horas no trabajadas a través de la distribución irregular de la jornada. Conforme al procedimiento del art. 3 DLA 10, tras obligado período de consultas con los representantes de los trabajadores se busca acuerdo colectivo pero, en su defecto, decide la empresa esta disponibilidad de horas. La distribución irregular de jornada ha sido, así, aprovechada, como vía de flexibilidad laboral ante la crisis, con esta vía singular.

\subsection{Subsidios especificos para trabajadores temporales y servicio doméstico y cobertura desempleo en pe- riodo de prueba y fijos discontinuos}

La extinción de contratos temporales, por vencimiento de término en los eventuales del art.15.1.b ET o formativos del art. 11 ET, y finalización de obra o servicio en los de obra o servicio del art. 15.1.a ET, está siendo una medida de ajuste de empleo en esta crisis, como demuestran los primeros datos de desempleo. La declarada interrupción del cómputo de la duración del contrato temporal en un ERTE del art. 5 DLA 9 tiene un alcance relativo porque muchos temporales no están incluidos entre los afectados. La eliminación de período de carencia de desempleo en ERTE puede haber facilitado esta entrada de temporales, pero en muchos casos los contratos habrán sido extinguidos antes, o lo serán luego, cuando se reanude la actividad pese a esta interrupción. Ello explica que el Gobierno haya reforzado, en el art. 33 DLA 11, la protección social por desempleo del colectivo con un subsidio específico de un mes en contratos, de al menos dos meses, sin la cotización necesaria para acceder a la prestación general.

Más gravosa es la situación de los trabajadores/as de servicio doméstico por la vulnerabilidad de sus contratos, sujetos a desistimiento del titular del hogar en el marco de relación laboral especial, sin protección social por desempleo. No pueden hacer ERTE y si se extinguen sus contratos no acceden a protección social por desempleo. Ello ha motivado también la aprobación de un subsidio extraordinario para este colectivo en los arts. 30-32 DLA 11.

Finalmente, el art. 22 DLA 15 ha cubierto con desempleo a los trabajadores que hayan visto sus contratos de trabajo extinguidos durante período de prueba a partir de 9 de Marzo y la DF 8.3 DLA 15 ha aclarado la protección extraordinaria de desempleo de los fijos discontinuos ante previsibles no llamadas, dado el enorme impacto, en este colectivo, de la crisis del COVID-19, sobre todo en sector hotelero y turismo, con vigencia hasta el 31 de Diciembre.

\subsection{Cese de actividad de autónomos con protección social}

En relación con los autónomos, finalmente, se reconoce, de manera extraordinaria, dada la situación de estado de alarma frente al COVID-19, en el art. 17 DLA 8, una prestación social por cese de actividad cuando su facturación descienda al menos un "75 por 100 en relación con el promedio 
de facturación del semestre anterior". Ello es importante en actividades suspendidas durante el estado de alarma que puedan impactar en autónomos, no teniendo que acreditar entonces esta reducción, y en descensos de consumo y demanda que reduzcan con este umbral los ingresos del colectivo. La cuantía es el 70 por 100 de base reguladora. Estará vigente hasta el 30 de Junio.

Los autónomos que mantienen actividad tienen moratorias de cuotas sociales, de Abril a Junio, en el art. 35 DLA 11, reformulado en la DF 10ª DLA 15, sin que se haya determinado ninguna exoneración.

\section{El desigual reparto de costes públicos y privados de las medidas adoptadas}

\subsection{Costes asumidos por el Estado}

El Estado absorbe buena parte del coste, en los ERTES, a través de protección social reforzada de los afectados y exoneraciones de cuotas de Seguridad Social en los de fuerza mayor, con importantes cuantías de renta pública. Dentro del paradigma de flexiseguridad, que determina esta acción política, resulta lógico transferir así costes laborales al Estado con el objetivo de salvar empleos. Las empresas se ahorran salarios y cotizaciones en una situación excepcional, los trabajadores reciben rentas públicas provisionales, y el Estado asume los costes públicos de este mantenimiento del empleo, ya por la vía suspensiva, ya por la reducción de jornada.

Los datos oficiales muestran una gran utilización de los ERTES en esta crisis. A mediados de Mayo, estos datos muestran que se han decidido o adoptado en torno a 450.000 que afectan a 3,5 millones de trabajadores. Esta enorme receptividad empresarial a esta herramienta de flexiseguridad laboral implica, que buena parte, de los costes laborales de la crisis sanitaria son asumidos por el Estado.

Sucede lo mismo con la prestación social por cese de actividad de los autónomos con caída significativa de ingresos. La amplia solicitud de este colectivo de la prestación, más de un millón de autónomos, con exoneración de cuotas, implica una sustancial asunción estatal de costes de la crisis.

A ello se debe añadir la cobertura social por desempleo extraordinaria en los fijos discontinuos, que ven interrumpida su actividad o no son llamados a trabajar debido a la crisis del COVID-19 afectados por ERTE o sin estar en un ERTE. El Estado va a soportar estos costes públicos en el colectivo, de gran importancia en zonas turísticas como Baleares, consciente de previsibles no llamamientos ante la merma de actividad empresarial.

El Estado tiene, entre sus funciones, ejercer de red aseguradora en las crisis económicas, más aún cuando declara el estado de alarma, como ha sucedido, con un inédito parón económico inducido para proteger la salud pública y lograr el máximo de confinamiento de la población en sus casas. Esta protección social específica libera costes a las empresas y asegura rentas a los trabajadores. En trabajadores por cuenta ajena, incluyendo fijos discontinuos, y autónomos, las cifras muestran que el Estado está cumpliendo esta función y protegiendo con rentas públicas muchas situaciones.

Siendo ello así, las empresas, autónomos y trabajadores por cuenta ajena están asumiendo, también, como veremos, costes significativos en esta crisis. De ninguna manera se puede afirmar que el Estado ha absorbido todo el impacto de la crisis, pues, más bien, ha existido un reparto de costes con el tejido productivo privado.

\subsection{Costes asumidos por las empresas}

Del lado de las empresas, en el marco de medidas analizado, sólo están sujetas a exoneración de Seguridad Social durante el estado de alarma las que efectúen un ERTE por fuerza mayor, además 
con la dura condición de mantener el empleo en seis meses posteriores. El coste de Seguridad Social es asumido en ERTE por causa empresarial relacionada con coronavirus y será proyectado, también, en empresas con ERTES por fuerza mayor que no mantengan empleo, lo que es previsible ocurra en muchas ocasiones. El DLA 18 ha delimitado esta cláusula de salvaguarda de empleo a afectados por ERTE y con importantes excepciones en despidos disciplinarios procedentes, extinciones por fin de contrato temporal o no llamamientos de fijos discontinuos, pero no excluye los despidos procedentes por causa empresarial de los arts.52.c y $51 \mathrm{ET}$, que es donde se concentrarán las extinciones por la caída de mercado y demanda. Resulta injusto cargar este coste a las empresas cuando su actividad ha sido paralizada por fuerza mayor y en una situación de recesión económica ajena al control de la empresa, al estar debida al COVID-19. Resulta también desproporcionada la exigencia de devolución de la totalidad de cuotas por incumplir este compromiso, siendo más razonable entender que se refiere, exclusivamente, a las cuotas de los trabajadores despedidos.

A estos costes sociales hay que añadir que la complejidad de los procedimientos articulados en ERTES han ocasionado gastos empresariales de tramitación y asesoramiento, con, en ocasiones, mucha inseguridad jurídica. Es difícil de calcular el coste real de la inseguridad jurídica pero ello ha sido soportado por el tejido productivo privado en un escenario de enorme dificultad económica. La división entre ERTES con procedimientos distintos, la acumulación de Decretos-Ley en escaso tiempo con cambios normativos, la aplicación a veces de lógicas distintas en el reparto de costes, la tramitación a veces dificultosa, y el riesgo a recibir sanciones por incumplir normas complejas, con previsiones normativas de alerta y control para ello, acumula costes e incertidumbres a las empresas que han utilizado estas herramientas flexibles para salvar empleos, hay que recordarlo, ante una inducida paralización productiva. Por ejemplo, articular una mesa sindical sectorial prioritaria en ERTES de empresas y centros sin representación de los trabajadores es añadir una tramitación incierta, que alarga plazos y crea riesgos de impugnación judicial, al tejido productivo de las Pymes que es el que necesita más apoyo. No parece que esta acumulación de costes inciertos y riesgos fuera lo más recomendable en este escenario de parón económico inducido por el Gobierno.

El permiso retribuido recuperable de los arts. 2 y 3 DLA 10, entre el 30 Marzo y 9 Abril, en actividades no esenciales, ha cargado costes añadidos en empresas que no pueden acudir al teletrabajo. Si bien los trabajadores tienen que recuperar estas horas retribuidas, sin trabajo, resulta previsible que en muchos casos no exista esta recuperación, entre otras cosas por falta de necesidad de trabajo, y el coste económico del parón económico lo habrá soportado el empresario. Sin ninguna cobertura pública, por cierto, porque ni siquiera ha existido una exención de cuotas sociales de este período temporal. El procedimiento del art. 3 DLA 10 tampoco facilita la recuperación porque no son horas disponibles por la empresa sino sujetas a un procedimiento de consultas con los representantes de los trabajadores que, donde no los hay, se vuelve a complicar con la prioridad de una mesa sindical sectorial. Se podría haber utilizado la fórmula del art. 34.2 ET, en defecto de negociación colectiva disponibilidad de esta bolsa de horas por la empresa, y, en cambio, se ha introducido una tramitación más compleja que en horas irregulares ordinarias, con estos períodos de consulta, si bien en última instancia sigue decidiendo la empresa.

\subsection{Costes asumidos por los trabajadores por cuenta ajena}

Del lado de los trabajadores/as, el acceso al desempleo con un 70 por 100 de base reguladora y el tope máximo de prestación social del Régimen General devalúa considerablemente su poder adquisitivo, pues no existe complemento salarial público, sin perjuicio lo establezca voluntariamente la empresa. Del mismo modo, los trabajadores/as que reducen su jornada al 100 por 100 por 
conciliación familiar sacrifican su salario durante la vigencia de la medida sin que se haya ofrecido ninguna renta compensatoria. Este margen de costes es asumido por los trabajadores directamente, con reducciones de ingresos que pueden ser muy significativas durante la crisis. La enorme receptividad de las empresas al uso de ERTES, antes expuesta, que afecta a unos tres millones y medio de trabajadores, evidencia este impacto económico. Con la incertidumbre que supone este escenario, donde la duración de los ERTES por fuerza mayor, tras el DLA 18, se desvincula ya del estado de alarma, hasta el 30 Junio o con prórrogas adicionales. Y muchos ERTES productivos han determinado duraciones amplias, en espera de una recuperación muy paulatina y gradual. En estos casos, el coste que debe soportar el trabajador puede multiplicarse porque el art.3 DLA 18 sólo parece prever hasta el 30 Junio la reposición de desempleo. Si no se corrige esta medida, los trabajadores irán consumiendo desempleo a partir del 30 Junio, en una situación de recesión económica que puede conllevar una próxima pérdida de su empleo.

Por su parte, en el permiso retribuido recuperable de actividades no esenciales, desde el 30 Marzo hasta el 9 Abril, existe un reparto de costes entre empresa y trabajador, sin asumir ninguno el Estado. La empresa debe mantener el pago de los salarios cuando no se trabaja, y el trabajador recuperar las horas no trabajadas cuando se reanude la actividad normal, con el procedimiento del art. 3 DLA 10. Como ya he expuesto, resulta previsible que sea la empresa quien asuma este coste económico porque serán horas en muchos casos no recuperadas. Si se recuperan se habrá activado este reparto de costes y si no lo soportará en exclusiva la empresa, sin ningún papel del Estado asegurador en una crisis.

Lo más preocupante, en cualquier caso, es el ajuste de empleo concentrado en trabajadores temporales. Como era previsible, ya los datos oficiales de Marzo y Abril muestran que el gran porcentaje, un 85 por 100, de empleos destruidos, ya en la primera fase de la crisis, provienen de trabajadores temporales. Son el colectivo laboral que más está soportando los costes de la crisis, pues pierden empleo, difícilmente van a encontrar otro en largo tiempo, y van consumiendo desempleo porque en ellos no opera la reposición exclusiva de los ERTES. De nada sirve interrumpir el cómputo de los contratos, como se ha adoptado en el art.5 DLA 9, si la gran mayoría no están en ERTES. Los contratos temporales se irán luego extinguiendo con este mismo efecto ampliado. Resulta oportuno el subsidio específico para los que no tienen cobertura social entre temporales con contratos de al menos dos meses, pero no hay que olvidar que un gran porcentaje de este colectivo tiene contratos de corta duración, sin que se haya previsto sumen varios contratos para acceder al subsidio. Puede haber casos, así, de falta de cobertura social. Habrá situaciones donde todo el coste de la crisis va a recaer en los trabajadores más vulnerables.

El propio Gobierno es consciente del impacto económico en los trabajadores de esta crisis, en distintos círculos de repercusión de costes, porque en el DLA 11 ha diseñado medidas de garantía de suministros de servicios básicos, moratorias de hipotecas y pagos de alquiler, con créditos en buenas condiciones del ICO, y prohibición de desahucios. Son medidas que compensan, con avales y dinero público, este impacto económico en los más vulnerables, pero que, a su vez, reflejan el propio impacto, que es así minimizado.

\subsection{Costes asumidos por los autónomos}

Finalmente, en los autónomos, el acceso a prestación por cese de actividad con un 70 por 100 de base reguladora, teniendo en cuenta que muchos cotizan por base mínima, tiene también un impacto significativo de devaluación de su poder adquisitivo. El parón productivo ha afectado a muchos autónomos cuyos ingresos se limitan a esta prestación social. 
Y los autónomos que mantienen actividad, con reducción de ingresos sin alcanzar el 75 por 100, no están exonerados de cuotas ni de pago de impuestos, pues tan sólo se han establecido, como he expuesto, moratorias.

Como han evidenciado las asociaciones profesionales de autónomos, la prestación social está siendo útil, pero este colectivo está soportando buena parte de los costes de la crisis. Además, los autónomos con empleados han vistos repercutidos también los costes empresariales, antes expuestos, con especial impacto de la incertidumbre de los procedimientos articulados y, en especial, del permiso retribuido ante el confinamiento total.

\subsection{Un reparto desigual de costes públicos y privados}

El análisis de distribución de costes públicos y privados de la crisis muestra un reparto desigual de su impacto.

Si bien el Estado asume parte de los costes, sobre todo en ERTES y fijos discontinuos, la repercusión económica en el tejido productivo privado es significativa, tanto en empresas y autónomos, como en trabajadores por cuenta ajena. El Estado ejerce una función de aseguramiento ante la crisis que, dado el volumen de ERTES, va a salvar millones de empleos, pero carga costes privados que pueden ser un lastre para la recuperación económica gradual y paulatina. El parón económico y productivo ha sido inducido por el Gobierno por motivos de salud pública pero los costes laborales no han sido asumidos íntegramente por el Estado sino repartidos, de manera desigual, entre empresas, autónomos y trabajadores.

No parece diferenciarse la respuesta pública de esta crisis a otras, como la del 2008, donde también el reparto de costes fue desigual, agravado además por la escasa presencia entonces de flexibilidad laboral. Hubo en ambas un fuerte ajuste inicial de empleo con temporales, dado nuestro modelo dual; hubo pérdida de poder adquisitivo de los asalariados en aquélla y lo está habiendo ya, vía ERTES, y habrá luego más, en ésta, vía reducciones de salario, en la tremenda recesión económica que se avecina; las empresas sufrieron entonces pérdidas importantes, que obligaron a ajustes de empleos y reestructuraciones productivas, sino concursos, y en ésta sucederá lo mismo; y los autónomos tendrán iguales consecuencias negativas en sus negocios que dará lugar a veces a cierres y quiebras. La diferencia con 2020 es que existe más flexibilidad laboral, lo que potencialmente va salvar más empleos que en 2008, que la política económica está asegurando liquidez, que minimizará daños, y que la UE está activando políticas de estímulo monetario y financiación pública. Pero el esquema de reparto de sacrificios de la crisis es bastante similar, sin que entonces, ni ahora, el Estado haya ejercido una función de aseguramiento íntegro de riesgos y costes. Determinado lenguaje ideológico -escudo social- no debería ocultar este hecho.

La singularidad, además, de esta crisis, es que ha sido el propio Estado quien ha inducido el parón económico y productivo por motivos de salud pública, lo que debería haber intensificado en mayor medida, al menos en esta primera fase, esta función pública de aseguramiento de riesgos y costes. No es una crisis de mercado, sino de salud pública con medidas instadas por el propio Estado para protegerla y que afectan a la economía. Esta premisa hace difícil la comparación con la crisis financiera de 2008 y, desde luego, lo que confirma, es que el Estado debería haber asumido, en mayor medida, la función aseguradora de riesgos y costes económicos. 


\section{4. ¿Cabía una alternativa más sencilla y con mayor soporte público?}

Partiendo de esta reflexión, cabe pensar si eran posibles alternativas más sencillas y con mayor soporte de aseguramiento público en una situación así. Es un ejercicio de hipótesis de pasado, que poco aporta a la más interesante reflexión de futuro, pero que merece la pena plantear en un plano teórico.

De inicio, se podrían haber articulado, junto con los agentes sociales, las actividades esenciales, con garantía de trabajo presencial, y no esenciales, sobre las que adoptar medidas graduales en función de decisiones de confinamiento. Con este esquema inicial, en actividades no esenciales, dependiendo del grado de las medidas, se podría haber articulado un modelo más sencillo con teletrabajo y, si ello no era técnicamente posible, acceso automático a ERTE por cualquier empresa con exoneraciones de cuotas y protección social por desempleo de los afectados, durante la duración de la medida de suspensión o restricción de actividad o prohibición de trabajo presencial. La empresa de actividad no esencial sólo tendría que haber declarado, ante la autoridad laboral, la imposibilidad de teletrabajo y sus trabajadores pasarían directamente a ERTE suspensivo o de reducción de jornada con esta protección social reforzada. Sin sospechas de ningún tipo porque el Estado habría ejercido de asegurador íntegro de costes y riesgos de las empresas afectadas por sus propias medidas, con el gasto público necesario.

En vez de dividir los ERTES en fuerza mayor o causa empresarial, dando protagonismo a la autoridad administrativa con una acumulación de procedimientos, se tendría, quizás, que haber simplificado el sistema de esta manera y con decisiones empresariales de ERTE, comunicadas al SEPE, a efectos de gestión del desempleo, para solventar una situación de excepcionalidad. Se habrían reducido así más costes a las empresas y garantizado a los trabajadores protección social en este tiempo provisional.

Lo mismo sucede con los autónomos. Quizás era más sencillo, en actividades no esenciales, ofrecerles a todos, al margen de su caída de ingresos, la opción por la cobertura social y exoneración de sus cuotas de seguridad social en este tiempo provisional. Se habría reducido el impacto de la crisis en su situación con la garantía pública de renta.

Era viable, en hipótesis, un modelo más sencillo de flexiseguridad, aunque hubiera sido mucho más costoso en gasto social de desempleo. En todo caso, este debate es ya estéril, y lo importante es cómo afrontar la recuperación económica con nuevas ecuaciones de reparto de costes públicos y privados.

\section{El reparto de costes de cara a la recuperación paulatina y gradual ${ }^{12}$}

\subsection{Facilitar ERTES}

La paulatina desescalada de medidas del estado de alarma, en fases graduales, y su futuro levantamiento definitivo, inaugurarán, también, un escenario inédito: la recuperación económica y empresarial tras este parón productivo. Este escenario va a suponer un replanteamiento de la distribución de costes laborales a medida que se vaya recuperando la actividad. Se da por hecho un gran impacto en desempleo, ya anticipado en la fase previa de la crisis, que tiene que ser socialmente atendido, y también es una evidencia que los ERTES van a seguir cumpliendo una función esencial para salvar

\footnotetext{
${ }^{12}$ Reproduzco básicamente las propuestas elaboradas en el documento de ESADE EC POL (dirección Toni Roldán) LAHERA FORTEZA,J;MATEO ESCOBAR,R, Politicas para mitigar el impacto laboral y social del Covid-19 en el periodo de transición, Abril 2020, accesible en web ESADE EC POL. No menciono algunas propuestas que posteriormente han sido articuladas en el DecretoLey 15 , como en trabajadores con período de prueba y fijos discontinuos.
} 
empleos. En ambos frentes habrá que aumentar la cobertura pública para evitar desequilibrios sociales y que el Estado cumpla, en mayor medida que hasta ahora, su función aseguradora de costes y riesgos en situaciones críticas.

Se debe aprobar una normativa específica que facilite los ERTES en esta recuperación, liberando de costes a las empresas para mantener empleos de cara al futuro' ${ }^{13}$. El DLA 18, que es la primera norma laboral de la desescalada, tiene buenas intenciones, al dividir los ERTES por fuerza mayor totales y parciales, con desafecciones graduales asociadas a exoneraciones porcentuales de cuotas, y un horizonte despejado hasta el 30 Junio. Pero esta acción política es claramente insuficiente si se quiere proteger el empleo y salvar empresas en la desescalada en medio de una recesión económica. Se debe profundizar en este objetivo con mayor ambición.

Los escenarios no van a ser ya de fuerza mayor, sino de caída sustancial de consumo, demanda y facturación, por lo que la herramienta es el ERTE por causa empresarial, sin necesidad de autorización administrativa. Ello va a relajar la acumulación de procedimientos administrativos de la primera fase de la crisis y ofrecer más margen de decisión a las empresas. El reto ahora es ofrecer el máximo de seguridad jurídica a las empresas durante esta segunda fase de la crisis. Se deben diseñar causas empresariales de ERTE adecuadas a esta realidad económica. Su diseño debe ser flexible y suficientemente amplio para que las empresas encajen en supuestos que se apartan de las reglas generales. Se debe contemplar de manera expresa lo que ya están haciendo muchas empresas, la posibilidad de afectar y desafectar trabajadores en el ERTE en función de la actividad e ingresos, ya previsto en ERTES de fuerza mayor parcial. La causa no va a ser fija y cierta sino incierta y gradual en el tiempo.

En este sentido, se deben facilitar los procedimientos para que las empresas tomen la decisión de suspensión contractual y reducción de jornada conforme a sus circunstancias, manteniendo vigentes los contratos de trabajo. Como en despidos y modificaciones contractuales se deberían diferenciar, por número de afectados, entre procedimientos individuales y colectivos, con o sin consulta con los representantes de los trabajadores. Cuando éstos existan, con períodos breves de consulta para alcanzar acuerdo sindical, decidiendo, en su defecto la empresa. Cuando no los hay, acudir a la regla general ya prevista en el art. 41.4 ET, una asamblea que elija directamente mesa sindical o comité ad hoc, sin la traba impuesta de dar prioridad a una mesa sindical del DLA 8.

La protección específica de desempleo, sin carencia y con reposición, debe continuar en estos nuevos ERTES, para proteger a los afectados. No se explica la limitación de medidas hasta el 30 Junio que se deduce del art. 3 DLA 18. Si los tiempos se alargan habrá que contemplar articular complementos públicos a estas prestaciones sociales. Se deben exonerar las cuotas empresariales de seguridad social a todas las empresas que utilicen estos nuevos ERTES específicos, con un compromiso de empleo, pero condicionado a las circunstancias económicas y productivas de cada sector, con normas claras, y que tan sólo incluya despidos improcedentes o nulos como incumplimiento.

La articulación de un fondo europeo de desempleo (SURE), destinado a medidas de reducción de horas de trabajo que salven empleos, inspirada en el modelo alemán, asegura la financiación de estas medidas. Pero es necesario facilitar los ERTES, en los términos expuestos, con esta reforma específica. O ERTES o despidos, esa va a ser en muchos casos la opción. Hay que facilitar, por tanto, con claridad, el gasto social que sea necesario, seguridad jurídica y contundencia, los ERTES. En ello estará una mejor distribución de costes de esta crisis porque si hay desempleo, se aumenta el impacto en los trabajadores, mientras que si, con renta pública, se aseguran empleos, el reparto de costes entre Estado, empresas y asalariados se equilibra.

${ }^{13}$ LAHERA FORTEZA,J, "Flexibilizar los ERTES para salvar más empleos”, Cinco Días, 14 Abril y "Proteger el empleo”, El País, 5 Mayo 


\subsection{Proteger a los más vulnerables}

Por su parte, ante el previsible gran aumento de desempleo derivado de una crisis sanitaria convertida en económica, en medio de una recesión global, es necesario aumentar la cobertura social, en especial la dirigida a los más vulnerables.

En un modelo dual como el español el ajuste inicial de empleo lo van a sufrir los temporales, como ya se está viendo. Por ello, va a ser fundamental aumentar la cobertura social de este colectivo. La medida adoptada hasta ahora del subsidio específico en contratos de al menos dos meses resulta insuficiente. Muchos temporales suman muchos contratos de breve duración y se debería extender el subsidio a quienes, al menos, con varios contratos, sumen un mes de cotización desde antes del estado de alarma.

Este tipo de medidas seguramente tendrán que ser compaginadas con rentas mínimas para todas las personas que no tengan prestación ni subsidio de desempleo. El debate se mezcla con el propuesto ingreso mínimo vital estructural pero se debe afrontar con rapidez y de manera finalista a los más perjudicados por esta crisis. Es tiempo de rentas mínimas coyunturales, no estructurales, aunque habrá que valorar el impacto del ingreso mínimo vital.

Finalmente, la distribución entre costes públicos y privados debe inclinarse mucho más hacia el Estado en el colectivo de los autónomos. Hay que replantear la prestación social por cese de actividad para atender situaciones de caída de ingresos sin la alta exigencia de un 75 por 100, por ejemplo con la referencia de un 40 por 100. Hay que alargar la vigencia de esta prestación social concebida de manera coyuntural y excepcional. Hay que efectuar exoneraciones de cuotas sociales en los próximos meses en los autónomos, más allá de las previstas moratorias. En la línea de lo ya previsto, hay que intensificar los avales y créditos públicos en el colectivo, con ayudas económicas directas, para salvar pequeños negocios.

\subsection{Por un reparto más equitativo de costes}

En conclusión, la distribución de costes laborales en la primera fase de la crisis sanitaria, coincidente con el estado de alarma, ha sido desigual porque el Estado, pese a absorber la parte social del impacto, lo que es loable, no ha terminado de ejercer del todo su función aseguradora y ha desplazado, en exceso, costes al tejido productivo privado. Las empresas, autónomos y trabajadores por cuenta ajena han soportado demasiados impactos económicos negativos, que pueden lastrar la recuperación ante la prevista recesión de los próximos meses.

La segunda fase de la crisis es una oportunidad para reconsiderar esta distribución de costes laborales y que el Estado ofrezca más cobertura pública en su función aseguradora de riesgos, en una situación que va a ser dura y muy difícil. Como ha sido expuesto en este análisis, se deben, por ello, facilitar los ERTES liberando de más costes a las empresas, y se deben atender con rentas públicas todas las situaciones de necesidad de los perdedores de esta crisis, sobre todo trabajadores temporales y autónomos con pequeños negocios, de sectores especialmente dañados. 